\title{
Technology-Supported Teaching of Volumetric Analysis
}

\author{
Canan KOÇAK ALTUNDAĞ, Fatma ALKAN
}

\section{INTRODUCTION}

The trainee teachers need to receive practical training on the uses of educational technology before they join the profession (Harwood \& McMahon, 1997). Additionally, it is an undeniable fact that chemistry, which aims at reaching facts through exploration and technology; and utilizes those facts in daily life have a very important role in the world of education. Therefore, teachers are expected, on the one hand, to use their knowledge and skills, and on the other hand, present attitudes and values that befit a scientist, in order to achieve compatibility with technology whilst teaching chemistry.

\section{METHOD}

The study group of the research consists of 106 trainee teachers. The attitudes of the trainee teachers towards educational technology are determined via the "Attitude towards the Use of Technology in Education Scale" developed by Öztürk (2006). The "Attitude towards Chemistry Scale" is developed by Akçay, Feyzioğlu and Tüysüz (2003) in order to assess the attitude of students towards chemistry courses. The success of the trainee teachers is determined by the chemistry achievement test developed by the researchers.

\section{FINDINGS}

When the finding is examined, it is seen that there is a statistically significant difference between the attitude towards educational technologies pre-test and post-test scores of the trainee teachers in the treatment group following implementation. In other words, while the technology-supported instruction employed in the treatment group had an important impact on the increase of positive attitude of the trainee teachers towards educational technologies, it could be said that the traditional approach used in the control group was not influential. However, when the pre-test/post-test attitude scores of the trainee teachers in the treatment group following technology-supported instruction implementations are examined, significant difference at the sub-dimensions of "the reflections of the use of educational technologies upon the instruction processes" and "the use of technology in education and classroom management" is revealed. Additionally, in more specific analyses no statistically significant differences between the post-test averages on the attitudes of the trainee teachers in treatment and control groups towards educational technologies were encountered.

As can be seen in finding, an increase in the positive attitudes towards chemistry among the trainee teachers in the treatment group can be discerned following implementations. This result shows that while the technology-supported instruction employed in the treatment group had an important impact on the trainee teachers' development of positive attitudes towards chemistry, the traditional verification laboratory approach used in the control group has not been effective. According to the analysis results, there were no statistically significant differences between the treatment and control group trainee teachers' chemistry achievement pre-test averages. This result shows that before implementation there were no significant differences in the academic success levels of the treatment and control group trainee teachers on the topic.

When the finding is examined, it is seen that the chemistry success of the trainee teachers in treatment and control groups have increased following implementation and that the increase is statistically significant. This result shows that the simulation-supported and 
traditional verification laboratory approaches are effective in the increase of the trainee teachers' success in chemistry.

\section{DISCUSSION}

Past research shows that the efficient use of technology in education is influenced by certain variable such as the attitudes (Hong \& Koh, 2002; Sa'ari, Luan \& Roslan, 2005), experiences (Zhao, 2007), and beliefs (Çağlltay et.al., 2001). This study aims at examining the attitudes of the science major trainee teachers, who are obligated to teach chemistry courses in particular, towards chemistry courses and the use of technology in education. As a result of the research, it has been determined that technology-based instruction leads to an increase in the academic success on the topic of volumetric titration, and concomitantly, the development of positive attitudes among the students towards chemistry courses and technology. Literature review shows that researchers have been interested in the students' attitudes towards chemistry courses and done many studies on the relationship between student attitudes and various demographic features. For instance, the results of the study conducted by Nick and Urhahne (2004) revealed that students who took chemistry courses supported with 3-D simulations were more successful. As a result of the study conducted by Abraham and Williamson (1995), it is revealed that the use of animations in class made it easier for the students to understand the content and rendered their knowledge more permanent. In this study, it is maintained that the visual presentation of the causes of incidents relating to the subject of "Volumetric Titration" to the students, supported by instructional technologies may help the instruction of other topics as well and that it may have a positive impact on the attitudes of the students on the course and technology. 